\title{
A Literature Review of Statistical Teaching Research in Big Data Environment
}

\author{
Chunhua Han \\ Business School, Shandong University of Technology \\ Zibo, China \\ Email: 46095506 [AT] qq.com
}

\begin{abstract}
The arrival of the big data era brings not only opportunities but also challenges to statistics teaching. It is of great significance to explore the statistics teaching mode under the big data environment. Closely following the frontier of Statistics teaching research in the big data environment, this paper combs the literature on statistics teaching research in the big data environment. Through analysis, it is found that the statistics teaching should give consideration to "systematicness" and "pertinence" closely with the pace of the era, constantly cultivate big data thinking, and make good use of statistics, a "sharp tool" for mining data value, so as to better serve social development in the big data environment.
\end{abstract}

Keywords--- Big data environment, Statistics teaching, Review

\section{INTRODUCTION}

With the rapid development of Internet, cloud computing, artificial intelligence and IOT, the wide popularization of mobile terminals, the rapid development of e-commerce, logistics and other platforms, the extensive use of micro-blog (tweeter) and other social platforms, the data volume increases sharply ${ }^{[1][2][3]}$, which is changing the way we live and comprehend the world, changing the operation of markets, governments and organizations, becomes a source of new value creation $^{[4]}$, and an important strategic resource for social development ${ }^{[5]}{ }^{[6]}$. Statistics, as a sharp tool to dig "data value", has become a core course or compulsory course for many majors in colleges and universities across home and abroad, so it plays an important role. However, the arrival of the big data era brings both opportunities and challenges to statistics ${ }^{[7]}$, and set a higher demand for the training of statistics talents ${ }^{[8]}$. Considering the traditional statistics teaching can no longer meet the requirements of the development of the era, many scholars have swerved to the big data environment. Combing the relevant research on Statistics teaching in the big data environment, especially the frontier of Statistics teaching research in the big data environment, this paper is dedicated to the theoretical and practical research of Statistics teaching in the big data environment.

\subsection{Research on teaching system}

\section{RELEVANT RESEARCH}

Some scholars have discussed the Statistics teaching system in the big data environment. For example, Xue Gang (2021) proposed "changing teaching thinking, optimizing teaching content, connecting majors effectively, strengthening software application, combining multiple assessment methods etc ${ }^{[9]}$. Cai Jing et al. (2021) analyzed the practical teaching system in the big data environment and emphasized "combination of professional practice and innovative practice" and "combination of subject competitions and innovation activities ${ }^{[10]}$. Zhu Jixu et al.(2020) presented a four-sphere integrated practical teaching system of "curriculum practice - social practice - comprehensive training - graduation practice"[11]. Jiang Liufang (2019) suggested a three-optimization teaching system of "thinking optimization, mode optimization and content optimization"[12]. Cheng Sheng (2018) offered some measures to reconstruct the teaching system and content, innovate the teaching mode and pay attention to the practical links ${ }^{[13]}$. Additionally, Pan Baoguo (2016) constructed a practical teaching system from different dimensions of professional curriculum, practical teaching mode, assessment system, teaching base construction, innovation incentive, graduation design, dual qualified teacher training, platform construction etc ${ }^{[14]}$. It can be seen that the "teaching system" of statistics involves many aspects, such as curriculum, society, training, graduation, platform, assessment, incentive and so on. These aspects complement each other and form a perfect statistical teaching system.

\subsection{Research on Statistics teaching from major perspective}

Other scholars have explored the statistics teaching mode in the big data environment from "major perspective". For example, Wang Huifang (2021), Zhan Haoyong (2021) and Zhou Jingmiao (2021) pointed out that the traditional statistics teaching in economics and management majors can not keep pace with the era such as alienation of theory and practice, 
single teaching methods, and put forward multi-dimensional teaching, practical teaching, efficient assessment system, converted teaching methods, open circular teaching, internship and other coping strategies ${ }^{[15][16][17]}$. In addition, Gu Jianhua (2016) proposed the Statistics curriculum system for economics and Management Majors, including five subsystems: elective subsystem, practice subsystem, case subsystem, application subsystem and basic subsystem ${ }^{[18]}$. Liu Shirui et al. (2020) ,taking psychology and education as example, studied statistics teaching in the big data environment and pointed out that "content, method and thought" are the key elements of Statistics teaching in the big data environment ${ }^{[19]}$. Zou Yuye (2019) took "shipping" major as example to analyze the statistics teaching under the background of big data, and put forward a five-sphere integrated statistics teaching mode of "objective - content - Method - means - Assessment ${ }^{[20]}$. Deng Xiaoqin (2020) explored into the Statistics curriculum reform model from "finance" major, pointed out problems in the teaching of financial statistics, such as "incomplete system", "limited teaching materials", "rigid model" and "few cases", and put forward the strategy of "optimization expansion mixing quantification" [21]. Zhang Huidong (2019) analyzed the Statistics teaching mode under the big data background of social security major, and gave the realization ways through "interest orientation", "multi teaching forms", "multi-dimensional evaluation", "being skilled and networked" [22]. Zhang

Ning (2017), immersed in the statistics teaching mode of "health management" under the background of big data, concluded health statistics teaching should cultivate applied statistics talent in health, and improve the teaching level by "simplifying derivation and emphasizing application, multi case teaching and statistical thinking training to meet the era needs ${ }^{[23]}$. Tang Zaixiang (2017) discussed the new teaching mode of medical statistics in the big data environment, and put forward strategies such as focusing on data driving, breaking through weak links, cultivating big data thinking, fresh case teaching, project-based teaching and so on ${ }^{[24}$. Li Suo et al. (2017) analyzed the "new form" and "new thinking" of Statistics teaching for biology majors, and pointed out that biostatistics teaching should adhere to the principle of "from life and making complexity simple", and effectively combine heuristic case teaching and inquiry case teaching, which is conducive to improving the quality and effect of Statistics teaching ${ }^{[25]}$. Li Guanjun et al. (2015) analyzed the reform mode of statistics course for logistics major, and pointed out that current logistics industry has become an important source of

big data, and statistics a sharp tool for analyzing logistics data, with also some problems in the current statistics teaching, such as weak professional relevance and content divorced from the era ${ }^{[26]}$. Therefore, he proposed "strengthening the cognition of big data, understanding the universality of basic statistical methods , perceiving professional cases of statistics from three aspects of Statistics major. Based on a comprehensive analysis, it is found that statistics teaching and research is involved with economics and management, finance, psychology, social security, aviation management, logistics, health management, biology and other majors, ranging across different majors of liberal arts, engineering and medicine, which share both "Commonness" and "characteristics". Therefore, it is rich and colorful to do research from major perspective.

\subsection{Research on teaching evaluation}

Some scholars have also studied statistics teaching in the big data environment from the perspective of teaching evaluation. For example, Peng Jiaying (2020) studied the teaching quality evaluation under the background of big data, believed that the teaching quality evaluation should include two aspects: monitoring analysis and evaluation analysis of online teaching quality, pointed out that targeted teaching design and efficient utilization of online teaching data are conducive to improve the quality of online teaching ${ }^{[27]}$. Sun Rong (2020) proposed an evaluation index system of statistics teaching ability in the big data era, including three primary indicators of "teaching level - professional knowledge - data literacy" and 11 secondary indicators, then made an empirical analysis by using AHP (analytic hierarchy process) ${ }^{[28]}$. Wang Zhenlei (2019) analyzed the current situation of Statistics teaching from teaching methods, curriculum system and practical teaching, and constructed the "wisdom" teaching mode of statistics under the big data environment from training objectives, curriculum, teaching evaluation ${ }^{[8]}$. Liang Lei (2017) believed that the teaching ability of statistics in the big data environment can be improved and evaluated from three aspects: the new curriculum system, the relationship between old and new knowledge, and the focus of national statistics ${ }^{[29]}$. It can be seen that the evaluation system of statistics teaching involves teaching, knowledge, literacy, supervision, objective, curriculum etc. From the perspective of method, AHP is effective.

\subsection{Research on talent training}

"Talent training", as an important content of statistics, has also been stressed by scholars. For example, Fu Zichun (2020) discussed the training mode of composite talents of Statistics major under the background of big data, and put forward the trinity training strategy of "curriculum design optimization - teaching method informatization - resource integration and competition participation $^{[30]}$. Zhang Chen et al. (2018), focusing on the problem of "disconnection from reality" in the teaching and talent training of Statistics major under the background of big data, put forward three measures for talent training of big data statistics, including"enhancing responsibility consciousness", "demand-oriented optimization of curriculum setting" and "active teaching mode"[31]. Xue Jing (2018) pointed out that statistics teaching in colleges and universities inclines to the cultivation of "theoretical" talents, which is contradictory to the demand of "comprehensive" talent in the era of big data, and therefore put forward a talent training mode of "strengthening teacher comprehensive ability", "open teaching", "student multifaceted ability training" and " school enterprise cooperation ${ }^{[32]}$. Wan Yuanyuan (2018) , taking the statistics course software "R language" as example, studied the training mode of Statistics "applicationoriented" talents in the big data era, and found it is the systematic learning of R language and constantly stimulating students' interest and creativity that help the combination of "theory" and "practice" and the cultivation of application- 
oriented talents ${ }^{[33]}$. Chen Yizhi (2016) studied "statistical thinking" in the context of big data, pointed out that statistical thinking, as a way of thinking to understand the world, has the same basic status with philosophy and mathematics, and believed that cultivating statistical talents in the environment of big data requires three abilities: systematic thinking ability, dialectical thinking ability, and logical thinking ability ${ }^{[34]}$. To sum up, shows that the talent training in statistics should integrate theory with practice, interest with creativity in respect of curriculum optimization, teaching informatization, competition participation and demand orientation.

\subsection{Research on teaching methods and strategies}

Some scholars have explored statistics teaching in the big data environment from the perspective of "teaching methods". For example, Han Jingshu (2019) raised "teaching team construction", "teaching content optimization" and "effective connection with data mining Courses" as the three magic weapons to improve the teaching methods of statistics courses under the background of big data ${ }^{[35]}$. Wu Dongwu et al. (2017) ], focusing on "modular teaching", constructed the teaching mode of management decision-making (including several modules such as data preprocessing, data processing, data information, management decision-making), which enriched and improved the statistics teaching method system under the environment ${ }^{[36]}$. Gao Kaiyan (2018) conducted statistics experiment teaching practice in big data environment on Excel platform,meanwhile, analyzing the advantages and shortcomings of the platform ${ }^{[37]}$. Guo Yingchun (2016) pointed out some problems in the current statistics teaching, such as "more theoretical and less vivid" , "separation of software use and theory teaching", and then raised countermeasures such as "case teaching", "combination of theory and practice", "stimulating innovative consciousness" and "adapting to the era demands ${ }^{[38]}$. Zhang Qian (2020), taking "Applied Statistics" as example to analyze the "achievement-oriented" statistics teaching reform mode under the big data environment, proposed a new statistics teaching mode including "de-conceptualization teaching", "exploratory teaching" and "Data-Driven practice teaching" [39]. Miao Jianhua et al. (2020) proposed the teaching method of combining "online teaching" (relying on "theol" and "cloud class" platform) and "offline teaching" (adopting the mode of "theory + practice + experiment)" ${ }^{140]}$.

Other scholars have studied statistics teaching in the big data environment. For example, Sun Xin et al. (2017) who pointed out that the advent of the big data era has brought a great impact on the traditional statistics teaching mode, put forward teaching strategies such as "shifting theory teaching to project solution", "focusing on network channels" and "teaching students according to their aptitude"[41]. Rong Zhuqing et al.(2017) proposed the strategies of "admiring class application", "big data technology to realize personalized teaching" and "following the three principles of systematization , applicability and pertinence " in view of the problems existing in the teaching of Applied Statistics ${ }^{[42]}$. Dou Dengquan et al. (2018) ,aware of higher requirements for all aspects of statistics teaching in the big data era, proposed a four-sphere response strategy of "teaching objectives - teaching contents - teaching methods - Teaching Assessment ${ }^{[43]}$. Gu Xiaoyan (2019) , analyzing the application-oriented teaching mode under the background of big data in management statistics , proposed three reform strategies of "teaching content optimization", "application orientation" and "concentration on process assessment ${ }^{[44]}$. Additionally, Li Aijie (2016) proposed the strategies of "breaking the inherent thinking mode", "basic teaching + curriculum content expansion", "innovative teaching mode" and "cultivating big data thinking", to cultivate "applied" and "compound" talents ${ }^{[45]}$.

It is found that the teaching methodology of statistics should lay emphasis on the combination of "online and offline", of "team building and teaching content optimization", of "software and theory", of "de-concept - inquiry - data-driven", and of "systematization - applicability - pertinence".

\subsection{Conclusion}

\section{CONCLUSION AND ENLIGHTENMENT}

It is concluded that the existing research range wide, from the "teaching system" and "teaching evaluation" of statistics to the "talent training" , "teaching methods and strategies" of statistics under the background of big data, from statistics teaching research with some certain "universal" significance among different majors, to statistics teaching research in"professional perspective", which comes to a research framework of Statistics teaching in the big data environment as shown in Figure 1. Under the support of "big data in different fields" (i.e. big data in different fields, such as government big data, enterprise big data, scientific research big data, education big data, and in terms of industry, such as commercial big data, industrial big data, agricultural big data, medical big data, financial big data, etc.), it can form a brand-new statistics teaching mode suitable for the big data environment in the best use of teaching system, effective teaching evaluation mechanism, correct teaching methods and reasonable talent training mechanism in line with specific majors or industries. 


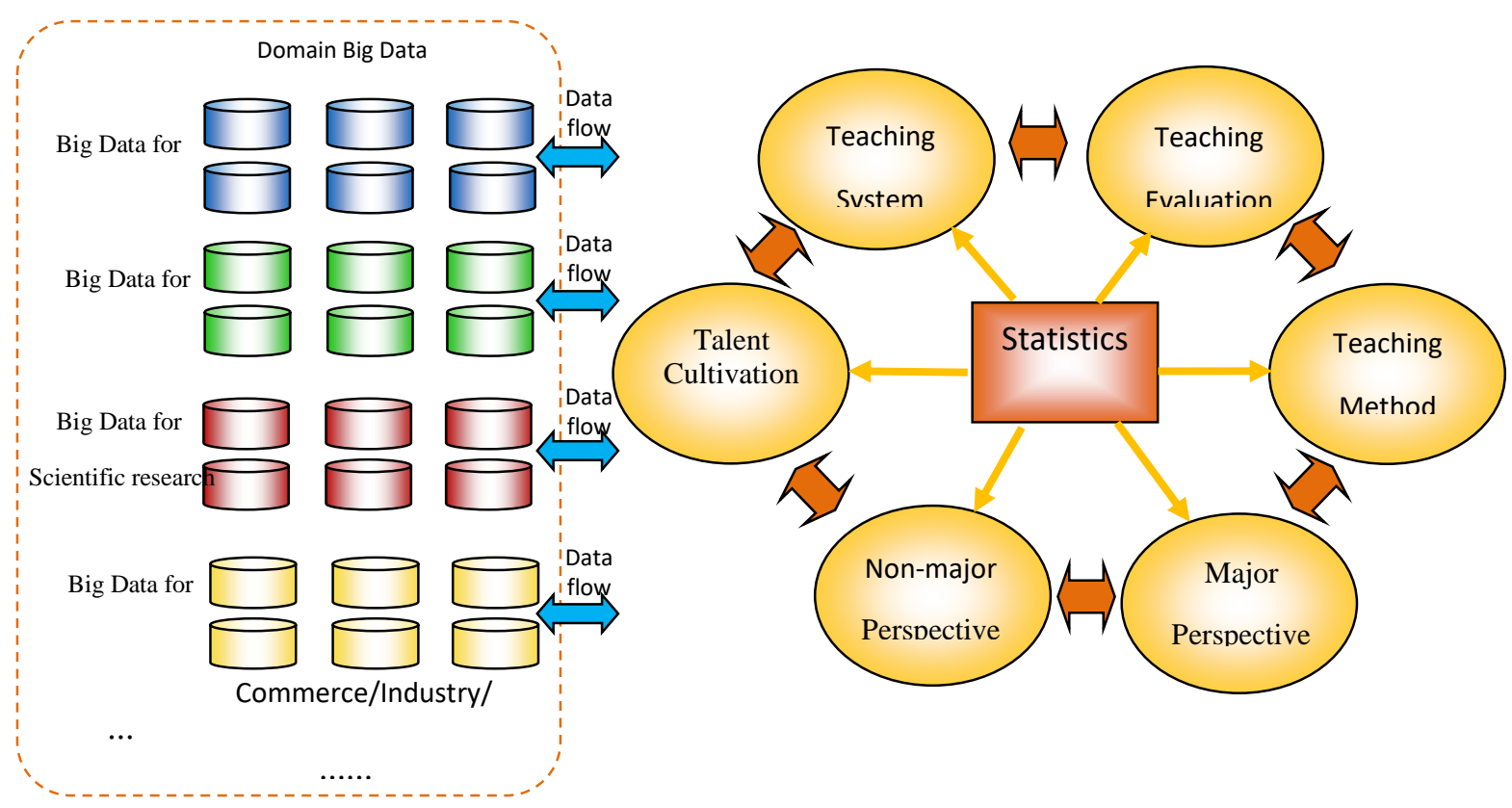

Figure 1 Statistics teaching framework in big data environment

\subsection{Enlightenment}

It can be enlightened from the above analysis: firstly, statistics teaching should concentrate on not only "systematicness" (that is, the teaching of statistics should be regarded as a "system engineering", including systematic content, methods and evaluation), but also "pertinence" (such as individualized teaching); secondly, statistics teaching should march to the era. For example, with the advent of 5G and AI, "big data" is characteristic of such as "intelligence","strong ubiquity", which raises new requirements for statistics teaching. Therefore, educators engaged in statistics teaching should follow closely with the development and strive to learn relevant statistical methods, technologies, platforms (software) in order to better meet the needs of the era; finally, in the process of statistics teaching, we should help teachers and students cultivate "big data thinking", establish an awareness that "big data is an important strategic resource", recognize the strategic value of big data, and utilize statistics to dig data value, so as to better serve the development of society.

\section{REFERENCES}

[1] Cheng Xiaobo, Zhou Min, Yu Shiyang, Li Junpeng. Marching towards a Fully Connected Intelligent World:5G Era·Big Data·Intelligence[M]. Beijing: Social Science Literature Press,2019:3-4

[2] Fu Yiping. On the opportunities, challenges and development trend of statistics in the era of big data[J]. China management informatization, 2016,19 (14): 245-246

[3] Guo Huadong. Scientific Big Data - A Footstone of National Strategy for Big Data[J]. Bulletin of Chinese Academy of Sciences, 2018,33 (8): 768-773

[4] Victor Mayer Schoenberg, Kenneth kukeyer, translated by Sheng Yangyan and Zhou Tao. Big Data Era: A Revolution that Will Transform How We Live,Work and Think[M]. Hangzhou: Zhejiang People's publishing house, 2013:27,45,6768

[5] Chen Xingwei, Shi Suncheng. Development and Thinking of Statistics in the Era of Big Data[J]. Journal of Fujian Computer, 2018,34 (12): 92-93

[6] Han Chunhua. Research on Statistics Teaching Model under the Dual Influence of Big Data Era and Artificial Intelligence[J]. Course Education Research, 2019 (40): 31-32

[7] Mao Jiangwei. Opportunities and Challenges of Statistics in the Era of Big Data[J]. Journal of Heihe University, 2017,8 (10): 56-57

[8] Wang Zhenlei. Exploration and Practical Research on "Wisdom" Teaching Mode and Cultivation of College Students' Innovative Ability under the Background of Big Data -- Taking Statistics as an Example [J]. Education Modernization, 2019,6 (71): 59-62

[9] Xue gang. Research on Statistics teaching Reform in Higher Vocational Education under the Background of Big Data[J]. Scientific consulting, 2021, \{4\} (07): 187-188

[10] Cai Jing, Jiang qingqiong, Gao Wei. Construction and Implementation of Practical Teaching System for Statistics Major in the Era of Big Data[J]. Science and Technology \& Innovation, 2021, \{4\} (12): 72-74

[11] Zhu Jixu, Chen Xiaoshi. How to Construct the Practical Teaching System of Economic Statistics Under The 
Background of Big Data [J]. Marketing Industry, 2020 (41): 94-95

[12] Jiang Liufang. On the Teaching Optimization of Statistics Courses in Colleges and Universities in the Era of Big Data

[J]. Asia-Pacific Education, 2019 (11): 48

[13] Cheng Sheng. Research on Undergraduate Teaching System of Statistics Under the Background of Big Data[J]. Education and Teaching Forum, 2018 (16): 169-170

[14] Pan Baoguo. Construction of Practical Teaching System of Statistics Major in Local Colleges and Universities in the

Era of Big Data[J]. Journal of Higher Education, 2016 (19): 46-47

[15] Wang Huifang. Research On the Reform and Innovation of Statistics Curriculum for Economics and Management Majors Under the Background of Big Data [J].The Science Education Article Collects, 2021 (06): 128-130

[16] Zhan Haoyong, Feng Jinli. Research on the Construction of Open Circular Teaching System of Economics and Management Statistics Under the Background of Big Data [J]. Modern Business Trade Industry, 2021,42 (19): 129-131

[17] Zhou Jingmiao. Research on the Design of Statistical Practice Teaching System for Economics and Management Major in the Era of Big Data [J]. Science \& Technology Vision, 2021 (13): 160-161

[18] Gu Jianhua. Construction of Statistics Curriculum System for Economics and Management Majors in the Era of Big Data [J]. Education and Teaching Forum, 2016 (13): 54-55

[19] Liu Shirui, Li Xiangsu. Practice and Thinking on Teaching Reform of Psychological and Educational Statistics Under the Background of Big Data [J]. Survey of Education, 2020,9 (14): 116-117 + 144

[20] Zou Yuye. Research on the Teaching Reform of Statistics Major in Shipping Colleges and Universities in the Era of Big Data [J]. The Guide of Science \& Education, 2019 (35): 58-59

[21] Deng Xiaoqin. Teaching Reform of Financial Statistics in the Era of Big Data[J].Modern Business Trade Industry, 2020,41 (17): 211-212

[22] Zhang Huidong. Using Big Data To Innovate and Develop the Teaching Reform of Statistics Course of Social Security Specialty [J]. Education and Teaching Forum, 2019 (52): 96-97

[23] Zhang Ning. Thoughts on the Teaching of Health Management Statistics in the Era of Big Data[J]. Medical

Education Management, 2017,3 (06): 458-460

[24] Tang Zaixiang. Thoughts on Medical Statistics Teaching Under the Background of Big Data [J]. Journal of

Lianyungang Technical College, 2017,30 (03): 69-73

[25] Li Suo, Zheng Xin, Shan Xuesong, Zhao Jing. Research on Biostatistics Teaching Reform in the Era of Big Data [J]. Education Modernization, 2017,4 (48): 45-46+65

[26] Li Guanjun, he Shihong. Thoughts on the reform of teaching content of statistics course for Logistics Specialty in the era of big data [J]. Journal of Guangxi Normal University (Philosophy and Social Sciences Edition), 2015,36 (05): 125127

[27] Peng Jiaying. Exploration on Offline Teaching Quality Monitoring and Evaluation Under the Background Of Big Data -- Taking Statistics Course As An Example [J]. Survey Of Education, 2020,9 (37): 64-67

[28] Sun Rong. Quantitative Evaluation Of Teachers' Teaching Ability in the Era Of Big Data -- Taking Statistics Teachers As An Example [J]. Journal Of Chengdu Normal University, 2020,36 (05): 19-27

[29] Liang Lei. Research on Improving the Teaching Ability Of Statistics Under the Background Of Big Data [J]. Computer Products and Circulation, 2017 (08): $168+170$

[30] Fu Zichun. Research on Innovation Of Training Mode Of Composite Talents Majoring in Statistics Under the Background Of Big Data [J]. Chinese and Foreign Entrepreneurs, 2020 (14): 152

[31] Zhang Chen, Lu Yuan. Research on Teaching Practice Of Innovative Talents Majoring in Statistics Under the Background Of Big Data [J]. Education Modernization, 2018,5 (36): 102-104

[32] Xue Jing. Training Of Statistical Talents in Colleges and Universities in the Era Of Big Data [J]. Scientific and Technological Economic Market, 2018 (01): 182-184

[33] Wan Yuanyuan. Training Of Applied Talents in Independent Colleges in the Era Of Big Data -- Software Teaching Reform Based on Statistics [J]. Education Modernization, 2018,5 (02): 16-17 + 24

[34] Chen Yizhi. Statistical Thinking and Training Of Statistical Talents Under the Background Of Big Data [J]. Journal Of Fuyang Institute Of Technology, 2016,27 (04): 1-4

[35] Han Jingshu. Research on Teaching Methods Of "Statistics" Course Under the Background Of Big Data [J]. Education and Teaching Forum, 2019 (09): 178-179

[36] Wu Dongwu, Wang Runliang. Research on Statistics Teaching Methods in the Context Of Big Data [J]. Journal Of Higher Education, 2017 (15): 76-78

[37] Gao Kaiyan. Research on Experimental Teaching Of Statistics Based on Excel Platform Under Big Data [J]. Journal Of Higher Education, 2018 (04): 92-94

[38] Guo Yingchun. Research on Teaching Methods and Models Of Statistics in the Era Of Big Data [J]. Education Modernization, 2016,3 (32): 20-21

[39] Zhang Qian. Teaching Reform Of Applied Statistics Under the Guidance Of Achievements in the Era Of Big Data [J]. Market Forum, 2020 (06): 78-80 + 90

[40] Miao Jianhua, Han Xingguo, Song Junli. Exploration and Practice Of Mixed Teaching Mode Of Statistics Course Under the Background Of Big Data [J]. Western China Quality Education, 2020,6 (03): 111-112 
[41] Sun Xin, Yin Biao. Response Of Statistics Discipline Under the Background Of Big Data Era [J]. Statistics \& Decision, 2017, \{4\} (06): $2+189$

[42] Rong Zhuqing, Han Xiying. Research on Applied Statistics Teaching Strategies in the Context Of Big Data [J]. Education and Teaching Forum, 2019 (14): 263-264

[43] Dou Dengquan, Zhang Chaoqun. Coping Strategies Of Statistics Teaching in the Era Of Big Data [J]. Western China Quality Education, 2018,4 (18): 157-158

[44] Gu Xiaoyan. Research on Application-Oriented Teaching Reform Of Management Statistics in the Big Data Environment [J]. Education and Teaching Forum, 2019 (08): 119-120

[45] Li Aijie. Influence and Countermeasures Of Big Data Era on Statistics Courses in Colleges and Universities [J]. Education Modernization, 2016,3 (11): 66-69 